\section{LCoBe}

19 a 22 de outubro de 2014

Florianópolis/SC

\title{
HIDRÓLISE DE QUERATINA DE PELOS BOVINOS
}

\author{
F. SOUZA, M. GUTTERRES \\ Universidade Federal do Rio Grande do Sul, Departamento de Engenharia Química, Laboratório \\ de Estudos em Couro e Meio Ambiente \\ E-mail para contato: francksouza@ @otmail.com, mariliz@enq.ufrgs.br
}

\begin{abstract}
RESUMO - A presença de pelos dissolvidos contribui para a elevada carga orgânica dos resíduos de depilação do processamento de couro. No entanto, este material rico em queratina pode ser recuperado caso o pelo não seja degradado durante a etapa de caleiro. A hidrólise da queratina de pelos bovinos foi realizada neste trabalho com seis agentes químicos diferentes e também com matéria-prima obtida a partir de resíduos recuperados do processo de depilação hair-saving. Os testes demonstraram que é possível a reutilização dos resíduos para obtenção de proteínas com massa molar média de $20 \mathrm{kDa}$ e rendimento aproximado de $75 \%$, quando se utiliza peróxido de hidrogênio como oxidante ou rendimento de até $90 \%$ quando se utilizam os pelos não processados e sulfeto de sódio em uma rota redutiva. Os processos testados além de apresentarem redução do tempo de processamento e aumento do rendimento, também utilizam menos agentes químicos quando comparados aos processos convencionais de extração.
\end{abstract}

\section{INTRODUÇÃO}

No processamento de pele bovina pelos curtumes, os pelos são removidos na etapa conhecida como depilação e caleiro. Nesta operação, que ocorre em meio aquoso, são adicionados hidróxido de cálcio para promover a elevação do $\mathrm{pH}$ e o inchamento da derme, além de diversos insumos químicos para remover os pelos. Basicamente são dois os tipos de processo de depilação: com destruição dos pelos e com preservação (total ou parcial). Processos depilatórios com destruição dos pelos se utilizam de uma quantidade suficiente de agentes redutores para garantir a remoção e consequente dissolução da queratina, também chamados de processos hair-burning (Valeika et al., 2009). Sulfeto de sódio é o um dos agentes mais utilizados, por ser barato e eficiente no processo, no entanto a carga orgânica do efluente eleva-se por conta dos pelos que já não podem ser removidos por filtração (Souza, 2010). Os processos que preveem a recuperação deste material contam com uma rota química diferente e também com uma filtração durante a etapa de caleiro.

A queratina é uma família de proteína caracterizada pelo elevado teor de enxofre (presente nos aminoácidos cisteína e cistina) comuns na epiderme de mamíferos, aves, peixes e répteis, bem como em anexos cutâneos tais como pelos, penas, escamas, chifres e unhas (Neurath, 1966). Pelos são compostos por queratinas do tipo hard (elevado percentual de pontes dissulfeto) e são formados por diferentes estruturas: córtex, medula e cutícula (El Baba, Covington e Davighi, 2000). A cutícula é composta por camadas de $\beta$-queratina cujo objetivo é envolver o córtex (matriz) e proteger o pelo de 


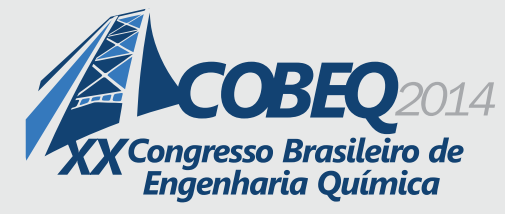

19 a 22 de outubro de 2014

Florianópolis/SC

danos físicos e químicos, por isto também possui uma camada lipídica que confere hidrofobicidade. No córtex estão presentes os filamentos intermediários (IF) e as proteínas associadas aos filamentos intermediários (IFAP) que compõem a matriz. A medula pode ocorrer em pelos mais espessos e é formada por uma coluna central de proteínas frouxamente ligadas. As queratinas que constituem a matriz possuem um maior teor de enxofre, cujo objetivo é dar coesão à estrutura, já as proteínas que formam os IF possuem um menor teor de enxofre e possuem conformação de hélice para dar suporte a estrutura. As primeiras possuem massa molecular variável entre 10 e $25 \mathrm{kDa}$ e as últimas entre 40 e $60 \mathrm{kDa}$ (Rouse e Dyke, 2010).

A hidrólise da queratina depende da quebra das pontes dissulfeto da cistina. São diversas as rotas que podem ser adotadas com este objetivo, no entanto a rota mais comum é a sulfitólise, na qual um agente redutor reage com a cistina para romper a ligação química (Cantera et al., 2004). Este é o mesmo princípio do processo depilatório hair-burning. Barone, Schmidt e Gregoire (2006) estudaram o efeito do vapor de ácido fórmico em queratinas de frango e concluíram que é possível solubilizar este material causando o rompimento da cistina. Abouheif et al. (1985) prepararam hidrolisado de queratina com uso de hidróxido de sódio para implementação nutricional da ração animal, bem como Costa et al. (2011), cuja aplicação foi voltada ao recurtimento de peles. As rotas oxidativas também foram estudadas por Marmer e Dudley (2006); Wortmann, Popescu e Sendelbach (2006), de acordo com De Guzman et al. (2011), a extração de queratinas por rotas oxidativas leva a proteínas com características diferentes da proteína nativa, uma vez que modificam as pontes dissulfetos formando grupamentos sulfônicos.

O hidrolisado de queratina é um biomaterial que possui um variado campo de aplicação, na qual suas propriedades irão determinar a finalidade. Além da vasta aplicação na área biomédica como suporte a crescimento de tecidos (Reichl, 2009) e scaffolds para enxertos ósseos (Hamasaki et al., 2008), este material pode ser aplicado também na produção de polímeros biodegradáveis (Barone, 2007; Vasconcelos, Freddi e Cavaco-Paulo, 2009) e aditivos para cosméticos (Barba et al., 2008).

Foram testados seis diferentes agentes químicos na hidrólise da queratina de pelos bovinos proveniente de duas fontes: pelos "in natura" e resíduos de pelos recuperados do processo de depilação. O objetivo de avaliar a possibilidade de recuperação desta proteína em um processo de extração acelerado e economicamente viável, para justificar o emprego de um processo depilatório sensivelmente mais caro, porém com benefícios ambientais e também econômicos no caso de comercialização da queratina extraída.

\section{MATERIAIS E MÉTODOS}

A matéria-prima, os pelos bovinos, foi obtida de duas formas distintas: pelos residuais do processo de depilação hair-saving, filtrados do efluente, e pelos não processados, removidos por uma tosquiadora elétrica de peles em estoque conservadas pelo processo de salga. Os primeiros foram filtrados do efluente com as características descritas na Tabela 1, cujo percentual mássico apresentado é baseado na massa de pele processada. 
Tabela 1 - Composição do efluente de depilação hair-saving em contato com os pelos (tempo de processo $2 \mathrm{~h}$, percentuais baseados na massa de pele processada)

\begin{tabular}{cc}
\hline Componente & Percentual \\
\hline Água & $50,00 \%$ \\
Tensoativo* (Borron T®) & $0,20 \%$ \\
$\mathrm{CaOH}_{2}$ & $1,50 \%$ \\
Auxiliar depilação isento de enxofre* (Erhavit HS®) & $1,20 \%$ \\
$\mathrm{Na}_{2} \mathrm{~S}$ & $1,50 \%$ \\
\hline
\end{tabular}

*Borron T® e Erhavit HS® são marcas registradas da TFL

Inicialmente a matéria prima foi lavada com tensoativo e extensivamente enxaguada. Lipídios foram extraídos com diclorometano em um extrator tipo Soxhlet seguindo a metodologia DIN EN ISO 4048. A moagem da amostra ocorreu em moinho de facas com granulometria ajustada em $0,50 \mathrm{~mm}$ e posterior moagem em moinho centrífugo com dois ajustes de granulometria subsequentes: $0,20 \mathrm{~mm}$ e $0,08 \mathrm{~mm}$. Após a moagem foi realizada a análise granulométrica das amostras e a caracterização do material, onde foram determinados os teores de água, lipídios, proteína e substancias inorgânicas, de acordo com as metodologias DIN EN ISO 4684, DIN EN ISO 4048, ASTM D 2868/2010 e DIN EN ISO 4047 respectivamente.

Os testes de hidrólise foram realizados em um thermomixer na temperatura de $55{ }^{\circ} \mathrm{C}$ (escolhida por ser a maior temperatura abaixo do ponto de ebulição comum a todos os reagentes) sob agitação de $250 \mathrm{rpm}$ e tempo de incubação de 3 horas. $\mathrm{O}$ pH foi ajustado quando necessário com soluções concentradas de hidróxido de sódio $(\mathrm{NaOH}, 3 \mathrm{M})$ e ácido clorídrico $(\mathrm{HCl}, 1 \mathrm{M})$. A matéria prima (pó de pelo) foi incubada em tubos de $1,5 \mathrm{ml}$ com concentração de $40 \mathrm{mg} / \mathrm{ml}$ de solução. Ao todo foram testadas sete diferentes soluções com concentração de $125 \mathrm{mM}$ do agente utilizado, conforme pode ser verificado na Tabela 2 .

Após a hidrólise, a suspensão foi centrifugada a 14.000 rpm durante 20 minutos à temperatura de $4{ }^{\circ} \mathrm{C}$ a fim de separar a solução contendo o material hidrolisado do pellet que contém a proteína não extraída. Subsequente à separação, os pellets foram enxaguados e centrifugados às mesmas condições por mais três vezes com a finalidade de remover possíveis agentes químicos e posteriormente foram liofilizados e armazenados. O sobrenadante foi separado da solução por meio de filtros centrífugos com membranas de polietersulfona e massa molar de corte de $10 \mathrm{kDa}$ (Vivaspin 2, GE heathcare), centrifugados a 12 minutos por $9000 \mathrm{rpm}$ e temperatura de $4{ }^{\circ} \mathrm{C}$. O material hidrolisado foi retido no filtro e o permeado, que é composto pelos íons em solução e fragmentos menores foi descartado. O hidrolisado foi então resuspendido em água destilada (mesmo volume da solução a fim de não alterar a concentração) onde foram coletadas as alíquotas para a eletroforese SDS-PAGE. Após foi realizada a liofilização das amostras para determinação da massa recuperada e rendimento da extração.

Com relação aos testes, além da caracterização da matéria prima, foi realizada a determinação da concentração de proteína hidrolisada, sua caracterização com base no peso molecular, de acordo com ensaios de eletroforese SDS-PAGE, conforme metodologia descrita por Zoccola, Aluigi e Tonin (2009). 
Tabela 2 - Descrição das soluções de hidrólise testadas

\begin{tabular}{cccc}
\hline Solução & $\begin{array}{c}\text { Concentração da } \\
\text { solução }(\mathrm{mM})\end{array}$ & $\mathrm{pH}$ & Descrição \\
\hline 2- mercaptoetanol & 125 & 10,0 & Agente redutor \\
Sulfeto de sódio & 125 & 12,5 & Agente redutor \\
Ácido tioglicólico & 125 & 10,0 & Agente redutor \\
Ácido fórmico & 125 & 1,5 & Solução ácida \\
Hidróxido de sódio & 125 & 12,5 & Solução alcalina \\
Peróxido de hidrogênio & 125 & 10,0 & Agente oxidante \\
Hipoclorito de sódio & 125 & 10,0 & Agente oxidante \\
\hline
\end{tabular}

\section{RESULTADOS E DISCUSSÕES}

A caracterização da matéria-prima com relação ao teor de umidade, substâncias extraíveis com diclorometano, proteína e cinzas é apresentada na Tabela 3. O teor de umidade de ambas as amostras manteve-se praticamente o mesmo, no entanto os demais parâmetros são diferentes. Estas diferenças são devidas ao tratamento químico pelo qual os pelos provenientes do resíduo de depilação sofreram previamente. O percentual de substâncias extraíveis com diclorometano (lipídios, neste caso) é menor para os pelos recuperados, o que é justificado pela ação dos tensoativos utilizados no processo durante a etapa de remolho. Já o teor de cinzas é sete vezes superior quando comparado aos pelos não processados. Este fato relaciona-se ao teor de material inorgânico presente na amostra de pelos recuperados, que se justifica principalmente pelo uso da cal durante a depilação. Com isso, observa-se um menor percentual de proteínas nos pelos recuperados quando comparado ao outro tipo. O teor de proteínas foi estimado de acordo com a análise de nitrogênio total de Kjeldahl (NTK), que prevê a multiplicação do teor de nitrogênio da amostra por um fator da literatura que é variável em função da proteína em questão. Para a queratina, o percentual de nitrogênio encontrado na literatura foi 15,80 , que corresponde a um fator de 6,33 (Edwards e Routh, 1944), bastante diferente daquele utilizado para determinação de substancia dérmica em couros $(5,62)$. A caracterização da matéria prima apresentou valores adequados de acordo com a literatura (Washburn, Gilmore e Fechheimer, 1958; Fraser, Macrae e Rogers, 1972), no entanto não existem dados que possam ser comparados para o pelo residual.

Tabela 3 - Médias e os respectivos desvios padrão para os percentuais mássicos de umidade, lipídeos, proteínas e cinzas das amostras

\begin{tabular}{cccccc}
\hline & Percentual & Água & Gordura & $\begin{array}{c}\text { Proteína } \\
(\mathrm{NTK})\end{array}$ & Cinzas \\
\hline Pelo in & Media & 12,79 & 1,19 & 82,92 & 1,46 \\
natura & Desv. Pad & 0,22 & 0,25 & 2,57 & 0,084 \\
Pelo & Media & 12,12 & 0,28 & 76,23 & 10,05 \\
residual & Desv. Pad & 0,058 & 0,0080 & 0,12 & 0,17 \\
\hline
\end{tabular}

A percentagem cumulativa de distribuição das amostras é mostrada na Figura 1A. A linha escura representa os pelos e a linha clara os pelos recuperados do processo, onde se verifica que mais 


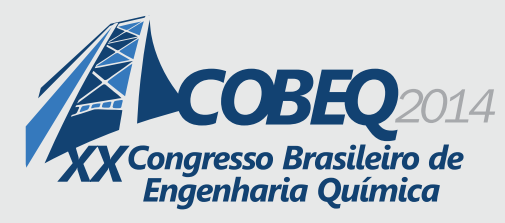

19 a 22 de outubro de 2014

Florianópolis/SC

de sessenta por cento da amostra possui diâmetro igual ou inferior a sessenta e três micrometros para ambos os casos. Um tamanho de partícula pequeno é importante para diminuir o tempo de reação da hidrólise, pois o aumento de área superficial facilita o contato do interior das fibras com o agente utilizado no processo.
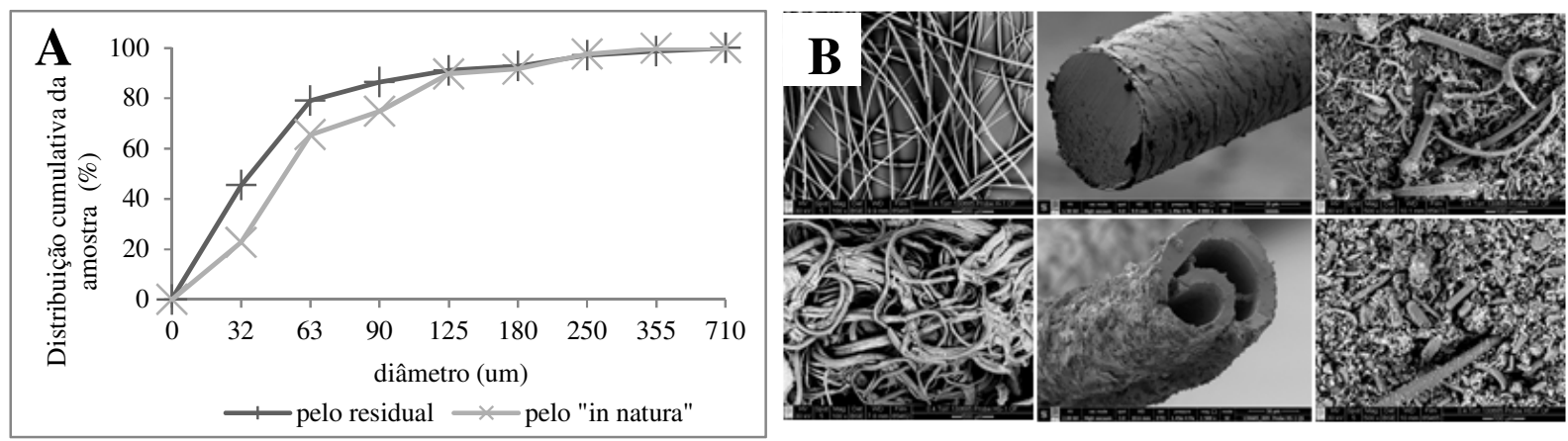

Figura 1 - (A) percentual de distribuição cumulativa das matérias primas após a moagem. A linha escura representa o material residual e a linha clara representa os pelos não tratados; (B) MEV das amostras de pelo (linha superior) e pelo recuperado (linha inferior). Na esquerda os pelos antes da moagem (100X), ao centro um corte transversal de um pelo (1500X) e na direita a distribuição granulométrica (500X).

Para finalizar a caracterização da matéria prima, são apresentadas na Figura 1B algumas imagens adquiridas em microscópio eletrônico de varredura (MEV). Na linha superior em diferentes ampliações e estágios podem ser vistos os pelos. Na imagem da esquerda pode ser visto o material coletado, no centro é apresentado um corte transversal onde pode ser observada parte da estrutura da cutícula, uma camada muito fina da superfície e a imagem da direita está mostrando o pó de pelo gerado por moagem juntamente com algumas partículas de tamanho maior.

A linha inferior apresenta as imagens dos pelos residuais. Apesar de não serem dissolvidos ao longo do processo depilatório é visível a modificação ocorrida neste material. A imagem da esquerda mostra os pelos mais grossos que aqueles visualizados na linha superior, o qual se explica pelo efeito de inchamento causado durante o processo. A imagem central mostra um fenômeno observado em alguns casos. Para alguns pelos a estrutura interna estava ausente e a cutícula apresenta um inchamento considerável. Esta observação esta de acordo com a afirmação anterior de que o teor proteico é menor para os pelos residuais, devido à presença de cal e a menor quantidade de proteína na amostra, que foi parcialmente perdida no processo de depilação. Por fim, a imagem da esquerda demonstra a distribuição granulométrica, bastante semelhante ao caso anterior, como comprova o gráfico da Figura 1A.

A concentração final dos testes após a extração da queratina é apresentada na Figura 2A. Para a maioria dos testes foi extraída mais queratina do pó de pelo original do que do pó de pelo recuperado, com exceção ao teste com peróxido de hidrogênio, como será discutido posteriormente. O percentual de queratina extraída é apresentado na Figura 2B. Para o cálculo deste valor foi levado em consideração os percentuais de proteína presentes na matéria-prima que estão apresentados na Tabela 3. Observa-se que a grande maioria dos testes possui rendimento inferior a $60 \%$, no entanto os testes 


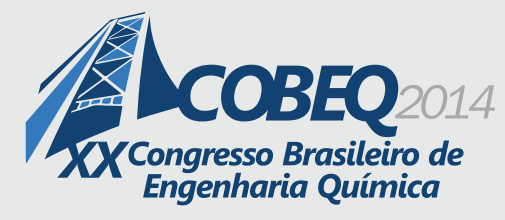

com pó de pelo em sulfeto de sódio e com o pó do pelo residual em solução com peróxido de hidrogênio apresentam rendimentos de 90 e $75 \%$ respectivamente. Trabalhos similares de extração de queratina em penas de frango, além da utilização de soluções mais complexas que contém reagentes adicionais, como a ureia ou tioureia em soluções de até $8 \mathrm{M}$ e atmosfera inerte de nitrogênio apresentam rendimento menor ou tempos de extração mais elevados (Yamauchi et al., 1996; Moore et al., 2006).
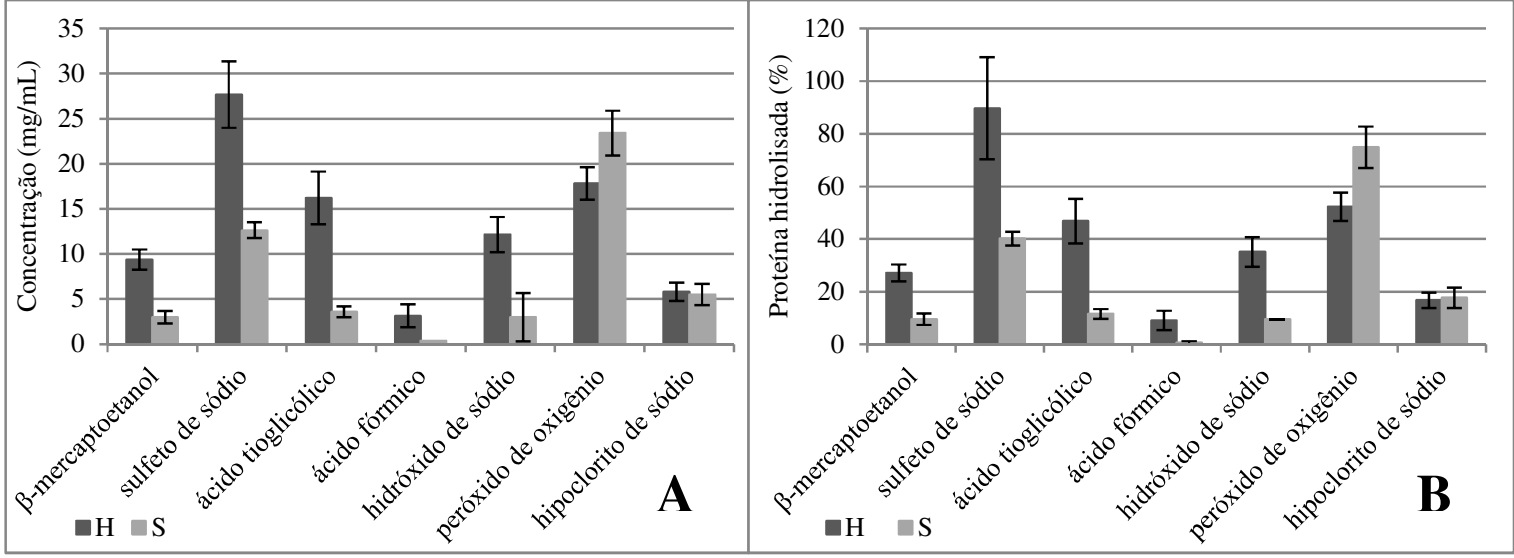

Figura 2 - (A) Concentração média das soluções após os testes de hidrólise; (B) Percentual de queratina extraída com base na massa de proteína adicionada ao início dos testes de hidrólise. As colunas claras representam os testes com os pelos residuais e as colunas escuras os testes com os pelos não tratados.

Por fim, são apresentadas as imagens do gel da eletroforese SDS-PAGE das amostras na Diversos géis apresentam uma banda localizada próximo a $20 \mathrm{kDa}$, de acordo com Popescu e Höcker (2007) corresponde às chamadas proteínas associadas aos filamentos intermediários (IFAP), que possuem massa molar variada entre 6 e $35 \mathrm{kDa}$.

Como mencionado anteriormente, os testes que utilizaram pelos apresentaram um rendimento superior na maioria dos casos, isso se deve ao fato de que o aminoácido cistina, presente nos pelos é normalmente convertido em lantionina em pH muito elevados (Blackburn e Lee, 1956). A lantionina é um aminoácido muito mais estável que se forma após o rompimento da ponte dissulfeto (Cantera, 2001). Este fenômeno pode ter ocorrido neste caso, uma vez que cal foi utilizada no processo depilatório que originou os pelos recuperados. Para os testes com peróxido de hidrogênio, este fenômeno não foi observado uma vez que o mecanismo de reação é distinto daquele que ocorre para os agentes redutores, no entanto ainda não foi completamente elucidado.

Figura 3, observam-se, três comportamentos na corrida das amostras no gel: o primeiro tipo, com respeito às colunas $1,2,5,10,11$ e 12 corresponde à ausência de proteínas na faixa em questão por duas razões distintas: não houve hidrólise das proteínas ou ocorreu a destruição das mesmas em fragmentos menores, como por exemplo no caso da solução com ácido fórmico e solução com hidróxido de sódio, respectivamente; observou-se também a presença de bandas difusas ao longo de todo o gel, como nas colunas 3, 6 e 7, indicando a presença de proteína de massa molar variada ao longo de toda a corrida, ou apenas em um determinado trecho, como no caso das colunas 4, 8, 9, 13, 


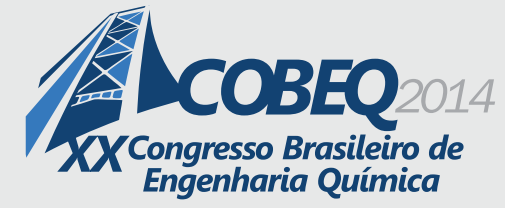

14, cujas bandas difusas aparecem abaixo de $45 \mathrm{kDa}$.

Diversos géis apresentam uma banda localizada próximo a $20 \mathrm{kDa}$, de acordo com Popescu e Höcker (2007) corresponde às chamadas proteínas associadas aos filamentos intermediários (IFAP), que possuem massa molar variada entre 6 e $35 \mathrm{kDa}$.

Como mencionado anteriormente, os testes que utilizaram pelos apresentaram um rendimento superior na maioria dos casos, isso se deve ao fato de que o aminoácido cistina, presente nos pelos é normalmente convertido em lantionina em pH muito elevados (Blackburn e Lee, 1956). A lantionina é um aminoácido muito mais estável que se forma após o rompimento da ponte dissulfeto (Cantera, 2001). Este fenômeno pode ter ocorrido neste caso, uma vez que cal foi utilizada no processo depilatório que originou os pelos recuperados. Para os testes com peróxido de hidrogênio, este fenômeno não foi observado uma vez que o mecanismo de reação é distinto daquele que ocorre para os agentes redutores, no entanto ainda não foi completamente elucidado.

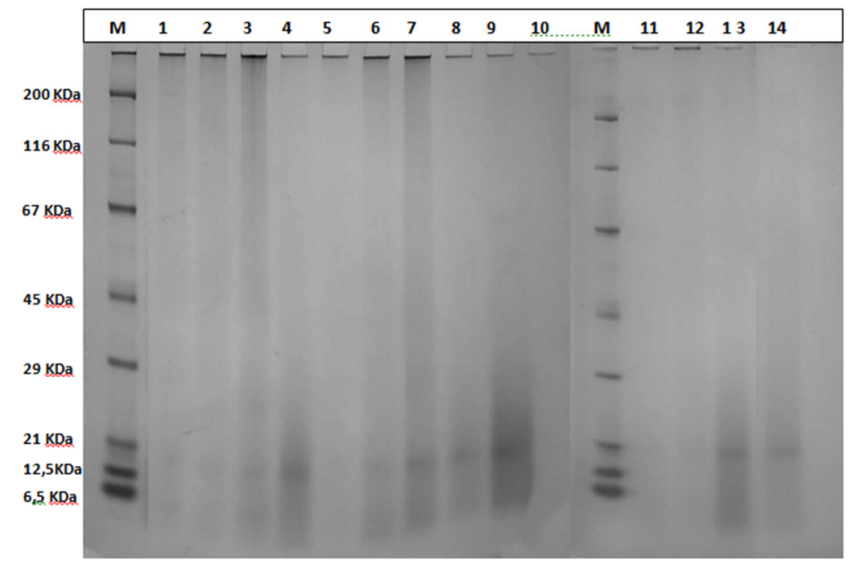

Figura 3 - SDS Page das amostras. Os índices M representam os marcadores, cuja massa molar pode ser vista à esquerda. Nas colunas 1 e 3 são apresentadas as amostras tratadas com ácido tioglicólico (pelos recuperados e pelos, respectivamente), as colunas 2 e 6 representam o tratamento com 2-mercaptoetanol (pelos recuperados e pelos, respectivamente), nas colunas 4 e 9 as amostras tratadas com peróxido de hidrogênio são apresentadas (pelos e pelos recuperados, respectivamente), nas colunas 5 e 11 podem ser vistos os resultados para os testes tratados com ácido fórmico (pelos recuperados e pelos, respectivamente), as colunas 7 e 14 são representativas das amostras tratadas com sulfeto de sódio (pelos e pelos recuperados, respectivamente), nas colunas 8 e 12 são apresentadas as amostras tratadas com hipoclorito de sódio (pelos e pelos recuperados, respectivamente) e por fim, nas colunas 10 e 13, são demonstradas as amostras tratadas com hidróxido de sódio (pelos recuperados e pelos, respectivamente).

\section{CONCLUSÃO}

Assim como para a queratina proveniente de penas de aves, também é possível realizar a extração de queratina de pelos bovinos. Alguns dos métodos testados demonstraram-se eficientes simples e rápidos para este fim, quando comparados às tecnologias existentes para o substrato pena. $\mathrm{O}$ uso de agentes redutores apresentou melhores resultados de extração, sendo que dentre estes, sulfeto 


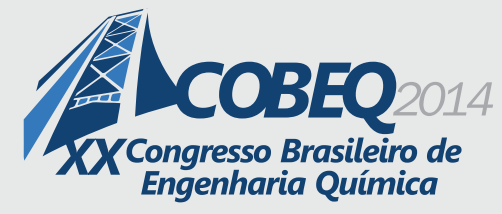

de sódio apresentou melhor resultado seguido de ácido tioglicólico e 2-mercaptoetanol. Ácido fórmico não foi adequado para a hidrólise na faixa de $\mathrm{pH}$ estudada. Hidróxido de sódio foi extremamente reativo e dissolveu totalmente a proteína em pequenos peptídeos. O uso de hipoclorito de sódio como agente oxidante também não gerou bons resultados, no entanto o peróxido de hidrogênio demonstrou-se eficiente com os pelos reaproveitados.

A hidrólise dos pelos in natura apresentou maior rendimento quando comparada à hidrólise do material residual, o que se explica pela formação de lantionina, que ocorre durante o processo hairsaving e dificulta a hidrólise. No entanto, este fenômeno não foi identificado para a reação com peróxido de hidrogênio.

Ainda que alguns métodos demonstraram-se ineficientes, a hidrólise com sulfeto de sódio em pelos in natura e com peróxido de hidrogênio em pelos recuperados, respectivamente, atingiu níveis de recuperação de proteína de $90 \%$ para o primeiro caso e $75 \%$ para o segundo, sendo que as queratinas extraídas apresentam massa molar média de $20 \mathrm{kDa}$ e correspondem às chamadas proteínas associadas aos filamentos intermediários (IFAP).

\section{AGRADECIMENTOS}

Os autores agradecem à FAPERGS (Edital FAPERGS 04/2012 - Programa PqG) pelo apoio financeiro e ao CNPq pela concessão da bolsa de pesquisa.

\section{REFERÊNCIAS}

ABOUHEIF, M. A.; BASMAEIL, S.; METWALLY, H.; MASOUD,S. Chemical preparation of $\mathrm{NaOH}$, Keratin hydrolysate for improving the nutritive value of wheat straw. An Feed Sci and Techn, v. 13, n. 34, p. 215-225, 1985.

BARBA, C.; MENDEZ, S.; RODDICK LANZILOTTA, A.; KELLY, R.; PARRA, J.L.; CODERCH, L. Cosmetic effectiveness of topically applied hydrolysed keratin peptides and lipids derived from wool. Skin Research and Technology, v. 14, n. 2, p. 243-248, 2008.

BARONE, J. R. Plastics from poultry feathers. Industrial Bioprocessing, v. 29, n. 5, p. 8, 2007.

BARONE, J. R.; SCHMIDT, W. F.; GREGOIRE, N. T. Extrusion of feather keratin. Journal of Applied Polymer Science, v. 100, n. 2, p. 1432-1442, 2006.

BLACKBURN, S.; LEE, G. R. The reaction of wool keratin with alkali. Bioch et bioph acta, v. 19, n. 3, p. 505-512, 1956.

CANTERA, C. S. Hair-saving unhairing process: Part 2. Immunisation phenomenon. Journal of the Society of Leather Technologies and Chemists, v. 85, n. 2, p. 47, 2001.

CANTERA, C. S.; GARRO, M.L.; GOYA, L.; BARBEITO, C.; GALARZA, B. Hair saving unhairing process: Part 6 stratum corneum as a diffusion barrier: Chemical-mechanical injury of epidermis. Journal of the Society of Leather Technologies and Chemists, v. 88, n. 3, p. 121-131, 2004.

COSTA, J.; PITREZ, P.R.; ROCHA, C.; FREITAS, O.M.; CRISPIM, F.; DELERUE-MATOS, C.; GONÇALVES, M.P.; CRISPIM, A. Estudo da obtenção do hidrolisado queratínico do pelo de bovino e sua aplicações como agente de recurtume. II Simpósio Internacional sobre 
gerenciamento de resíduos agropecuários e agroindustriais - II SIGERA. Foz do Iguaçú 2011.

DE GUZMAN, R. C.; ROCHE, C.; MERRIL, M.R.; RICHTER, J.R.; HAMZI, R.I.; GREENGAUZROBERTS, O.K.; VAN-DYKE, M.E. Mechanical and biological properties of keratose biomaterials. Biomaterials, v. 32, n. 32, p. 8205-8217, ISSN 0142-9612.

EDWARDS, B.; ROUTH, J. I. Chemical studies on powdered keratins. J. of Biological Chemistry, v. 154, p. 4, 1944.

EL BABA, H. A. M.; COVINGTON, A. D.; DAVIGHI, D. The effects of hair shaving on unhairing reactions part 2: A new mechanism of unhairing. J. of the Society of Leather Technologies and Chemists, v. 84, n. 1, p. 48-53, 2000.

FRASER, R. D. B.; MACRAE, T. P.; ROGERS, G. E. Keratins: their composition, structure and biosynthesis. Thomas Springfield, IL, 1972.

HAMASAKI, S.; TACHIBANA, A.; TADA, D.; YAMAUCHI,K.; TANABE,T. Fabrication of highly porous keratin sponges by freeze-drying in the presence of calcium alginate beads. Materials Science and Engineering: C, v. 28, n. 8, p. 1250-1254, 2008.

MARMER, W. N.; DUDLEY, R. L. The oxidative degradation of keratin (wool and bovine hair). Journal of the American Leather Chemists Association, v. 101, n. 11, p. 408-415, 2006.

MOORE, G. R. P.; MARTELLI, S.M.; GANDOLFO, C.A.; PIRES, A.T.N.; LAURINDO, J.B. Chicken feather keratin: Extraction, characterization and films preparation., Ciência e tecn de Alimentos, v. 26, n. 2, p. 421-427, 2006.

NEURATH, H. The Proteins: Composition, Structure and Function, vol. 2, 1966.

POPESCU, C.; HÖCKER, H. Hair - The most sophisticated biological composite material. Chemical Society Reviews, v. 36, n. 8, p. 1282-1291, 2007.

REICHL, S. Films based on human hair keratin as substrates for cell culture and tissue engineering. Biomaterials, v. 30, n. 36, p. 6854-6866, 2009.

ROUSE, J. G.; DYKE, M. E. V. A Review of Keratin-Based Biomaterials for Biomedical Applications. Materials Science and Engineering C, v. 3, p. 16, 2010.

SOUZA, F. R. Aplicação de enzimas no processamento de couros: comparação entre processos químicos e coenzimáticos, Dissertação (Mestrado). PPGEQ - Depto de Engenharia Química, UFRGS, Porto Alegre, 145 p., 2010.

VALEIKA, V.; BELESKA, K.; VALEIKIENE, V.; KOLODZEISKIS, V. An approach to cleaner production: from hair burning to hair saving using a lime-free unhairing system. J. of Cleaner Production, v. 17, n. 2, p. 214-221, 2009.

VASCONCELOS, A.; FREDDI, G.; CAVACO-PAULO, A. Biodegradable materials based on silk fibroin and keratin. Biomacromolecules, v. 10, n. 4, p. 1019, 2009.

WASHBURN, R. G.; GILMORE, L. O.; FECHHEIMER, N. S. The chemical composition of cattle hair. I. The fat, ash and nitrogen content. The Ohio Jorurnal of Science, v. 58, n. 3, p. 3, 1958.

WORTMANN, F. J.; POPESCU, C.; SENDELBACH, G. Nonisothermal denaturation kinetics of human hair and the effects of oxidation. Biopolymers, v. 83, n. 6, p. 630-635, 2006.

YAMAUCHI, K; YAMAUCHI, A.; KUSUNOKI, T.; KOHDA, A.; KONISHI, Y. Preparation of stable aqueous solution of keratins, and physiochemical and biodegradational properties of films. Journal of Biomedical Materials Research, v. 31, n. 4, p. 439-444, 1996.

ZOCCOLA, M.; ALUIGI, A.; TONIN, C. Characterisation of keratin biomass from butchery and wool industry wastes. Journal of Molecular Structure, v. 938, n. 1-3, p. 35-40, 2009. 